\title{
Electrospray ion mobility spectrometry of intact viruses
}

\author{
John J. Thomas ${ }^{\text {a }}$, Brian Bothner ${ }^{\mathrm{a}}$, Joe Traina ${ }^{\mathrm{b}}$, W. Henry Benner ${ }^{\mathrm{c}}$ and Gary Siuzdak $^{\mathrm{a}, *}$ \\ ${ }^{a}$ The Scripps Research Institute, Center for Mass Spectrometry and Department of Molecular Biology, \\ 10550 N. Torrey Pines Rd., La Jolla, CA 92037, USA \\ ${ }^{\mathrm{b}}$ Berlex Biosciences, Richmond, CA 94806, USA \\ ${ }^{\mathrm{c}}$ Lawrence Livermore National Lab, Livermore, CA 94551, USA
}

\begin{abstract}
Characterizing supramolecular interactions offers significant challenges using NMR or crystallographic techniques either because of size limitations or the difficulty in forming suitable crystals, while mass spectrometry is largely limited to low resolution mass information. Here we report gas phase measurements of intact virus particles using electrospray ion mobility spectrometry with an accuracy in radial measurements that were sufficient to differentiate closely related species. In addition, measured diameters indicate that iscosahedral virus particles retain their structure in the gas phase as well as undergoing a slight compaction in the absence of solvent. Analysis of the human pathogen adenovirus represents the largest and most sophisticated biomolecular complex detected in the gas phase to date. These results, on a diverse set of viral systems, suggest that ion mobility spectrometry may have broad applications for the analysis of biological complexes.
\end{abstract}

\section{Introduction}

Direct structural characterization of large macromolecular complexes is a technically challenging problem and has generally required structural inference from the analysis of separate components of the complex. Recently, intact macromolecular non-covalent complexes (of mega-Dalton mass) have been directly observed by electrospray ionization (ESI) mass spectrometry analysis in combination with a time-of-flight mass analyzer and a novel charge detection device [1-3]. This ESI charge-detection mass spectrometer [1,4] provided the first mass measurements of intact viruses and suggested that ESI could also be used to examine structural features if coupled with ion mobility spectrometry (IMS).

In order for the application of IMS to multi-component protein complexes to be meaningful, tertiary and quaternary interactions must be retained in the gas phase. ESI has previously been demonstrated to generate intact non-covalent complexes in the gas phase $[5,6]$ and empty virus particles have been successfully mass measured [7]. Specifically, hapten binding by an antibody [8], stability of protein conformers [9] and enzymatic activity [10] in the gas phase all suggest that the native fold of a protein can be retained. It should be noted that gas phase binding affinities [11] and the distribution of folding intermediates [12] can differ from the solution conformation. Interestingly, the structure and infectivity of a virus (a mega-Dalton non-covalent nucleo-protein complex) were retained after electrospray ionization and mass selection [2].

The technique of IMS has primarily been used for the characterization of small molecules by correlating diffusion rate with size and shape [13,14]. Ion mobilities are measured by determining the time required for a pulse of ions to traverse a uniform electric field in the presence of a buffer gas $[15,16]$

\footnotetext{
${ }^{*}$ Corresponding author. E-mail: siuzdak@ scripps.edu.
} 
and the size of the particle is directly related to its mobility. A recent study successfully compared the diameter of 32 monomeric and multimeric globular proteins based on their ion mobility [17] and demonstrated the potential of IMS for studying intact virus particles. A second IMS study reported that the modal diameter of MS2 particles could be measured using IMS [18].

Viruses are an ideal model system for studying the gas phase conformation of proteins because a change in secondary, tertiary, or quaternary structure is likely to have a dramatic effect on the overall capsid architecture. Here we report the IMS analysis of four icosahedral viruses with sufficient accuracy and resolution to distinguish between similar virus species and even between identical capsids that package different RNA molecules.

\section{Experimental section}

Plants were inoculated from stocks of RYMV (ATCC PV-515) and CPMV by the direct application of virus to primary leaves. Infected secondary leaves were homogenized in $0.1 \mathrm{M}$ phosphate buffer $\mathrm{pH}$ 7.0 and filtered through two layers of cheesecloth. The extract was clarified by centrifugation at $15,000 \mathrm{~g}$ for 20 minutes. The final step was a (w/v) $\mathrm{CsCl}$ gradient. The samples were dialyzed against $25 \mathrm{mM}$ ammonium acetate at acidic (2.8) and neutral (7.4) pH. MS2 was purified as previously described [18].

IMS analysis was conducted using a GEMMA 3980 Macromolecule Analyzer (TSI Inc. Shoreview, $\mathrm{MN})$. Virus solutions $(0.1 \mathrm{mg} / \mathrm{ml})$ were infused into a moderately heated $\left(37^{\circ} \mathrm{C}\right)$ capillary at $50 \mathrm{nl} / \mathrm{min}$ in a solution of $25 \mathrm{mM}$ ammonium acetate. A sheath flow of nitrogen gas at $15 \mathrm{l} / \mathrm{min}$ assisted desolvation and the direction of the electrosprayed ions. A voltage of 1800 volts was applied to the electrospray needle, and the electrostatic classifier was scanned from 0 to $15 \mathrm{kV}$ to monitor the particle size range of interest. Virus particles were detected with an ultra-fine condensation particle counter detection.

\section{Results}

Four non-enveloped icosahedral viruses were examined in these studies: rice yellow mottle virus (RYMV), cowpea mosaic virus (CPMV), bacteriophage MS2, and the human pathogen adenovirus. RYMV, CPMV, and MS2 have single stranded RNA genomes [19]. RYMV and CPMV are plant viruses and MS2 is a bacteriophage. Adenovirus has a double-stranded DNA genome and is well known as a major contributor to human respitory aliments. We selected these viruses for analysis because they represent viruses from four families, infect three different phyla, have three different capsid architectures, and exemplify both RNA and DNA viruses.

RYMV is a member of the sobemovirus family of single stranded RNA plant viruses. The capsid is composed of 180 copies of a single protein arranged with $T=3$ iscoahedral symmetry [20]. The molecular weight of the protein capsid and packaged RNA is 8 mega-Daltons. RYMV was introduced to the gas phase from a $0.1 \mathrm{mg} / \mathrm{ml}$ solution in $25 \mathrm{mM}$ ammonium acetate. The IMS analysis was straightforward and gave a spectrum corresponding to a diameter of $28.5 \mathrm{~nm}$ (Fig. 1). This is slightly smaller than the diameter calculated from the crystal structure which is $29 \mathrm{~nm}$ across the 2-fold and $32.2 \mathrm{~nm}$ across the 5-fold axis [20]. Present in the spectrum are low intensity signals from smaller components ( $\sim 10$ and $20 \mathrm{~nm}$ ) which are possibly a result of viral particle degradation prior to or during the ESI process. Solution conditions (e.g., $\mathrm{pH}$, ionic strength, and viscosity) are critical for maintaining virus particle integrity, as well as providing robust electrospray signals. 

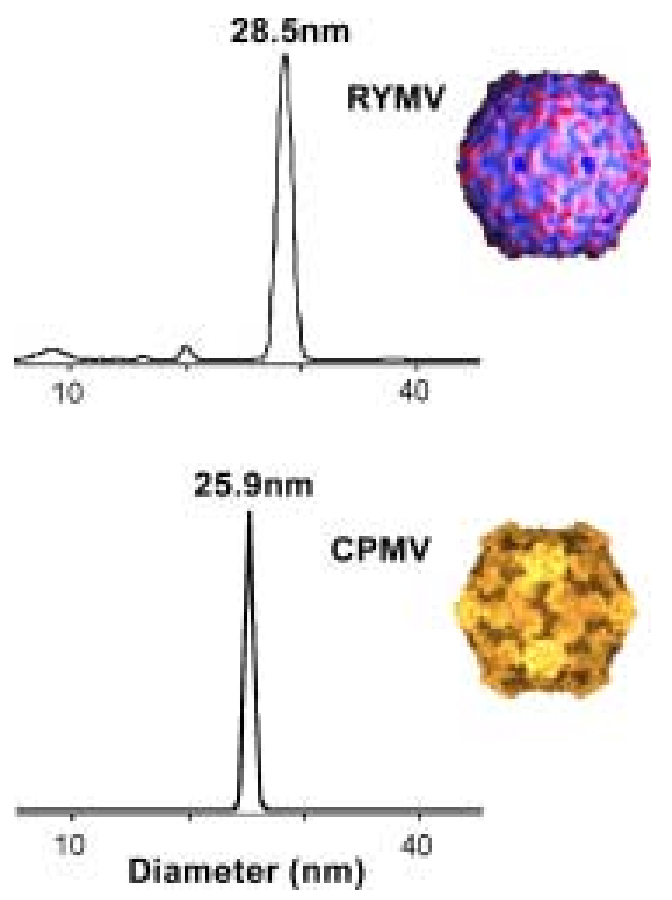

Fig. 1. Ion mobility spectra of virus particles. Top, RYMV analyzed from a solution of $25 \mathrm{mM}$ ammonium acetate at $0.1 \mathrm{mg} / \mathrm{ml}$. Bottom, purified CPMV-M. Models of the virus particles are based on electron cryomicroscopy data (Viper web site http://mmtsb.scripps.edu/viper/viper.html).

CPMV is also a single stranded RNA virus that infects plants. The capsid is composed of 60 copies of two different proteins arranged with pseudo $T=3$ icosahedral symmetry [21,22]. CPMV has a bipartate genome with two RNA's (3481 and 5889 nucleotides) which get packaged into separate capsids. When purified from host plants, three particle types can be separated by $\mathrm{CsCl}$ density centrifugation. These CPMV species are referred to as CPMV-T (no RNA), CPMV-M (small RNA), and CPMV-B (large RNA). CPMV-M analyzed from a $0.1 \mathrm{mg} / \mathrm{ml}$ solution produced a single molecular species with a measured diameter of $25.9 \pm 0.2 \mathrm{~nm}$ (Fig. 1). Structural models based on X-ray crystallography data for each of the CPMV particle types have the same icosahedral cross sections (28-32 nm) [23]. Interestingly, analysis of particles that package different RNA molecules revealed a difference in mobility (Fig. 2). The resolution of the measured diameters as full width at half maximum (FWHM) for both samples was 12 . This is consistent with a previous analysis of human rhinovirus [17]. While the resolution of the IMS was not sufficient to completely resolve the two species, a reproducible difference was detected. Unlike traditional electrospray ionization mass spectrometry, measurements of charge-reduced ions are independent of the charge distribution on the complex. However, the broad distribution common with electrospray mass spectral measurements of porous irregular biopolymer complexes most likely contributes to the peak width of electrospray ion mobility measurements [24,25].

To test whether IMS could be used to distinguish virus particles from a mixture, a solution containing RYMV and MS2 was analyzed. Like RYMV, the MS2 capsid is composed of 180 copies of a single protein with $T=3$ symmetry [26]. The crystal structure of MS2 has ordered RNA within the capsid, suggesting strong protein:RNA interactions and iscosahedral symmetry of the packaged genetic material. A 1:1 mixture of RYMV and MS2 was introduced into the instrument. These virus particles differ in size by only $4 \mathrm{~nm}(15 \%)$, yet could be differentiated with baseline resolution (Fig. 3). 


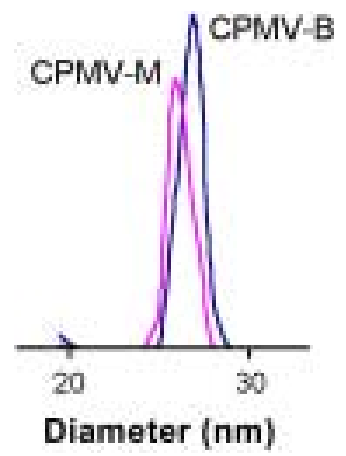

Fig. 2. Diameter of identical virus particles is altered by packaged RNA. CPMV-M ion mobility FWHM: $25.6-26.8 \mathrm{~nm}$, RNA $=3481$ nucleotides. CPMV-B ion mobility FWHM: $26.1-27.5 \mathrm{~nm}$, RNA $=5889$ nucleotides .

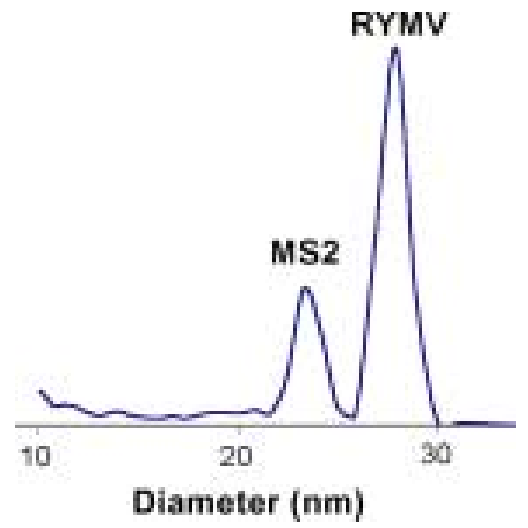

Fig. 3. IMS can be used to separate mixtures of virus particles. The RYMV and MS 2 capsid diameter differs by only $4 \mathrm{~nm}$, yet baseline resolution of the two particles was possible. MS2 modal diameter: $23.6 \mathrm{~nm}$, FWHM: $22.9-24.3 \mathrm{~nm}$. RYMV modal diameter: 27.9 nm, FWHM: 27.0-28.6 nm.

Non-enveloped viruses that cause human pathogenesis typically have a sophisticated capsid in part to avoid detection by the immune system. To test the potential application of IMS to health related viruses, Adenovirus a causative agent of respiratory ailments was analyzed. The adenovirus capsid contains 10 different proteins that assemble into 252 capsomers. Twelve of the capsomers form large spikes at the five-fold axis of symmetry. These protein spikes, protrude $\sim 10 \mathrm{~nm}$ from the surface and are involved in receptor binding. Of interest was how this type of capsid structure would effect IMS measurements of cross sectional area. Adenovirus has a diameter of 60-90 nm (with and without spikes) and was analyzed under the same conditions as the plant viruses (Fig. 4). The calculated diameter from the IMS experiment was $80 \mathrm{~nm}$. The spectrum of adenovirus was of lower resolution and lower signal to noise ratio than the other viruses analyzed. A number of factors including stability, charge state, and purity could be responsible for this.

\section{Discussion}

The gas phase mobility measurements of virus particles were consistent with the known icosahedral capsid architecture. These results confirm that non-covalent macromolecular structure can be maintained 


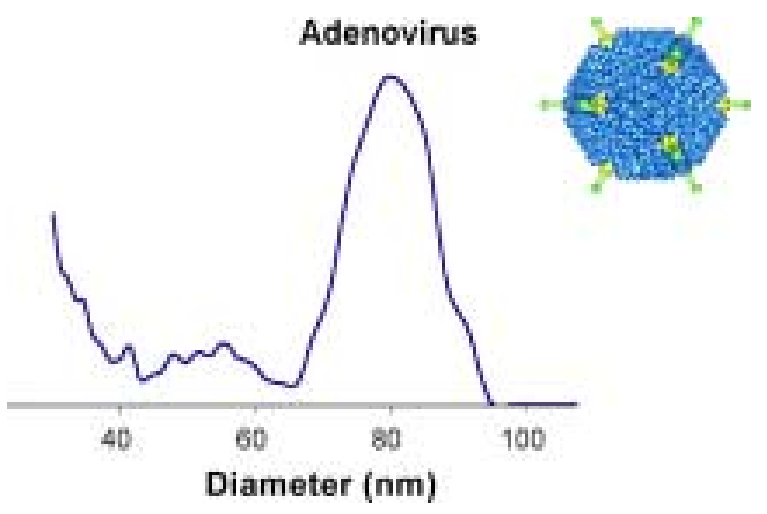

Fig. 4. The human pathogen adenovirus. Modal diameter: $79.1 \mathrm{~nm}$, FWHM: $72-88 \mathrm{~nm}$. The electron micrograph reveals the icosahedral capsid and spikes which protrude from the five fold axis (Viper web site http://mmtsb.scripps.edu/viper/viper.html).

in the gas phase. A rapid and sensitive method for the structural characterization of biologically relevant macromolecular complexes would be of general interest to health scientists. Currently, medium to high resolution techniques such as X-ray crystallography, electron microscopy, and SAXS require substantial commitments of time and money to generate structural information. The work presented here demonstrates the potential of IMS as a rapid and facile method for characterizing the shape of non-covalent complexes.

The calculated diameters of RYMV, MS2, and CPMV were within $15 \%$ of the values obtained from $\mathrm{X}$-ray models. It is of interest that the diameters from gas phase measurements were consistently smaller than solution phase estimates based on X-ray data. This is also consistent with the previous measurement of rhinovirus, which also was smaller than the X-ray model [17]. Protein crystals are typically $50-80 \% \mathrm{H}_{2} \mathrm{O}$, nearly all of which would be removed during the IMS electrospray/ionization process. Desolvation of the particle could result in an overall compaction of the structure as water was removed from protein:protein and protein:nucleic acid interfaces [27]. It is intriguing to consider the difference in the diameter of the two CPMV particles in this context. It is likely that the less dense packing of RNA in CPMV-M results in a more compactable particle when dehydrated. Packaged RNA has been shown to have a structural role [28] and can modulate capsid protein dynamics [29]. Further investigation of the gas phase radii of particles packaging different RNA molecules may lead to new insight about protein/nucleic acid interactions.

\section{Acknowledgements}

The authors would like to thank Tianwei Lin for providing the CPMV samples and Charles H. Wick for supplying MS2. This work was supported by NIH grant GM055775.

\section{References}

[1] S.D. Fuerstenau, W.H. Benner, J.J. Thomas, C. Brugidou, B. Bothner and G. Siuzdak, Angew. Chem. Int. Ed. 40 (2001), $542-544$.

[2] G. Siuzdak, B. Bothner, M. Yeager, C. Brugidou, C.M. Fauget, K. Hoey and C.M. Chang, Chem. Biol. 3 (1996), 45-48.

[3] S.D. Fuerstenau and W.H. Benner, Rapid Commun. Mass Spectrom. 9 (1995), 1528-1538.

[4] M. Frank, S.E. Labov, G. Westmacott and W.H. Benner, Mass Spectrometry Reviews 18 (1999), 155-186. 
[5] B. Ganem, T. Li and J.D. Henion, J. Am. Chem. Soc. 113 (1991), 8534-8535.

[6] V. Katta and B.T. Chait, J. Am. Chem. Soc. 114 (1992), 3992-3993.

[7] M.A. Tito, K. Tarsm, K. Valegardm, J. Hajdum and C.V. Robinson, J. Am. Chem. Soc. 122 (2000), 3550-3551.

[8] G. Siuzdak, J.K. Krebs, S.J. Benkovic and H.J. Dyson, J. Am. Chem. Soc. 116 (1994), 7937-7938.

[9] D. Suckau, Y. Shi, S.C. Beu, M.W. Senko, J.P. Quinn, F.M. Wampler, 3rd and F.W. McLafferty, Proc. Natl. Acad. Sci. USA 90(3) (1993), 790-793.

[10] P.A. Cameron, B.H. Davison, P.D. Frymier and J.W. Barton, Biotechnol. Bioeng. 78(3) (2002), 251-256.

[11] E.T. van den Bremer, W. Jiskoot, R. James, G.R. Moore, C. Kleanthous, A.J. Heck and C.S. Maier, Protein Sci. 11(7) (2002), 1738-1752.

[12] D.M. Horn, K. Breuker, A.J. Frank and F.W. McLafferty, J. Am. Chem. Soc. 123(40) (2001), 9792-9799.

[13] H.H. Hill, Jr, W.F. Siems, R.H. St. Louis and D.G. McMinn, Anal. Chem. 62 (1990), 1201A-1209A.

[14] D.F. Hagen, Anal. Chem. 51 (1979), 870-874.

[15] J.C. Tou and G.U. Boggs, Anal. Chem. 48 (1976), 1351-1357.

[16] Y. Liu, J.S. Valentine, A.E. Counterman, C.S. Hoaglund and D.E. Clemmer, Anal. Chem. 69 (1997), 728A-733A.

[17] G. Bacher, W.W. Szymanski, S.L. Kaufman, P. Zollner, D. Blass and G. Allmaier, J. Mass Spec. 36 (2001), $1038-1052$.

[18] C.H. Wick and P.E. McCubbi, Toxicology Methods 9 (1999), 245-252.

[19] C. Yassi, C. Ritzenthaler, C. Brugidou, C.M. Fauquet and R.N. Beachy, J. Gen. Virol. 75 (1994), 249-256.

[20] C. Qu, L. Lijas, N. Opalka, C. Brugidou, M. Yeager, R.N. Beachy, C.M. Fauquet, J.E. Johnson and T. Lin, Structure 8 (2000), 1095-1103.

[21] P. Van Wezenbeck, J. Verrer, J. Harmsen, P. Vos and A. van Kammen, EMBO J. 2(6) (1983), 941-946.

[22] G.P. Lomonossoff and M. Shanks, EMBO J. 2 (1983), 2253-2258.

[23] T. Lin, Z. Chen, U. Ramakrishnan, C.V. Stauffacher, J.B. Dai, T. Schmidt and J.E. Johnson, Virology 265 (1999), $20-34$.

[24] A.T. Da Poian, J.E. Johnson and J.L. Silva, J. Biol. Chem. 277 (2002), 47596-47602.

[25] E.J. Nettleton, M. Sunde, Z. Lai, J.W. Kelly, C.M. Dobson and C.V. Robinson, J. Mol. Biol. 281 (1998), 553-564.

[26] R. Golmohammadi, K. Valegard, K. Fridborg and L. Lilas, J. Mol. Biol. 234 (1993), 620-639.

[27] S. Leikin, D.C. Rau and V.A. Parsegian, Proc. Natl. Acad. Sci. USA 91 (1994), 276-280.

[28] L. Tang, K. Johnson, L. Ball, T. Lin, M. Yeager and J. Johnson, Nat. Struct. Biol. 8 (2001), 77-83.

[29] B. Bothner, A. Schneemann, D. Marshall, V. Reddy, J.E. Johnson and G. Siuzdak, Nat. Struct. Biol. 6 (1999), $114-116$.

[30] C.H. Wick and P.E. McCubbi, Toxicology Methods 9 (1999), 245-252. 


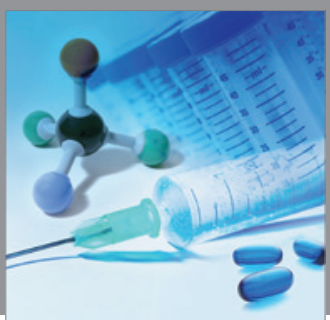

International Journal of

Medicinal Chemistry

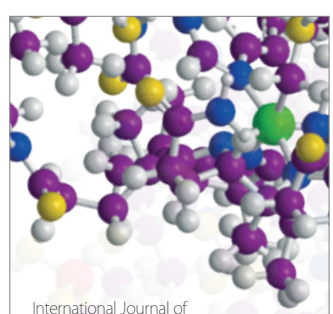

Carbohydrate Chemistry

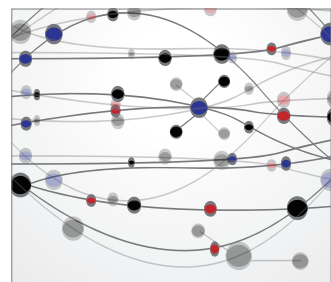

The Scientific World Journal
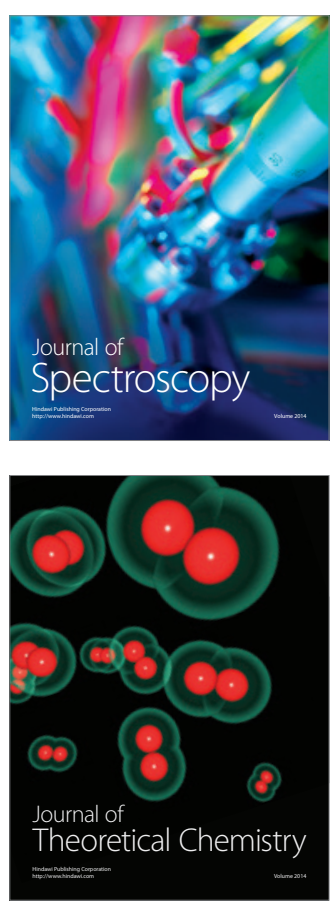
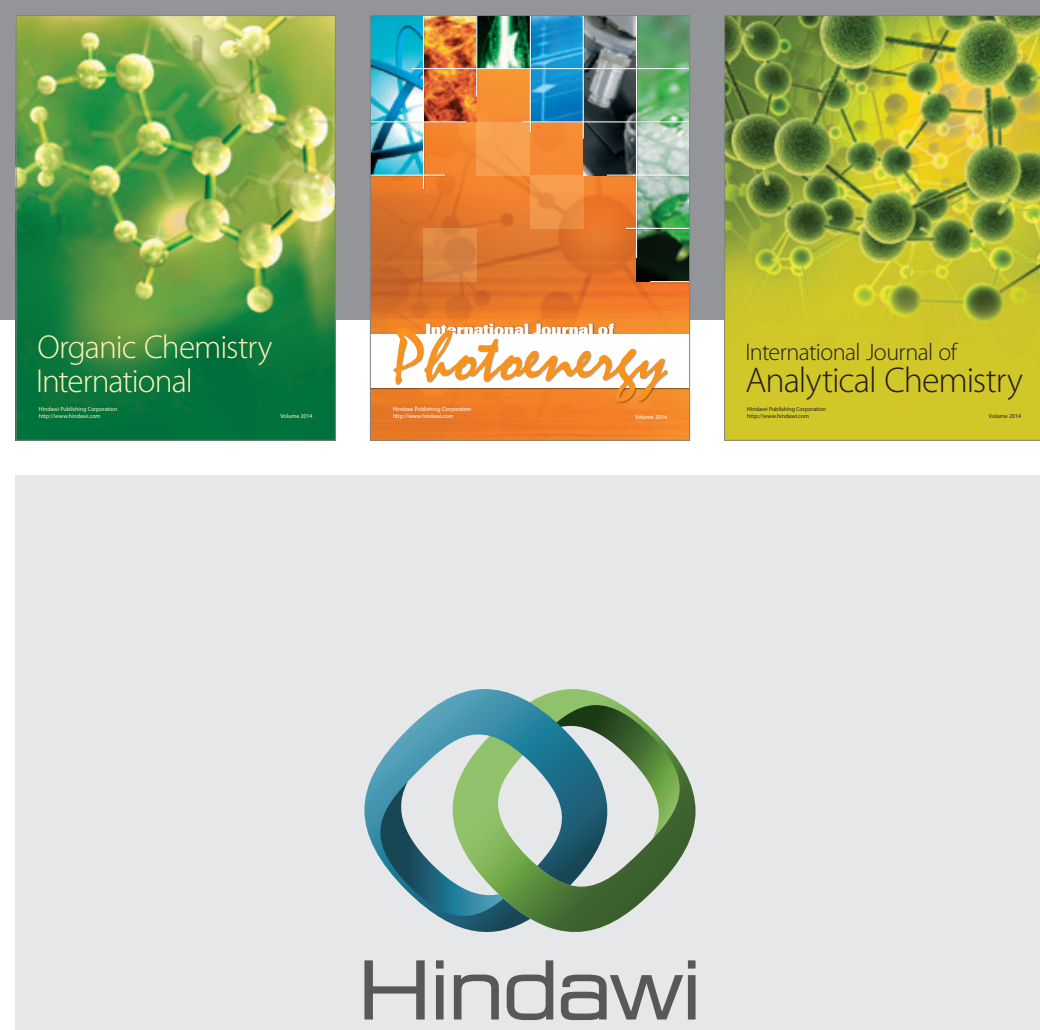

Submit your manuscripts at

http://www.hindawi.com
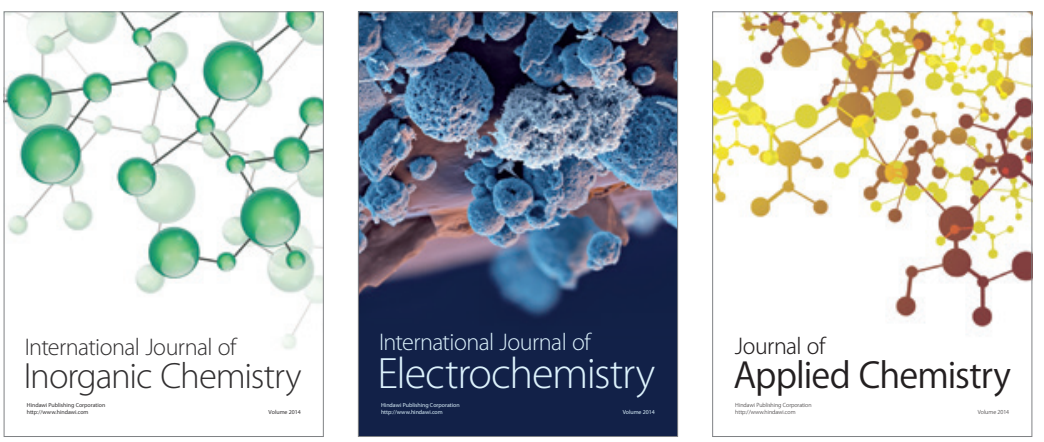

Journal of

Applied Chemistry
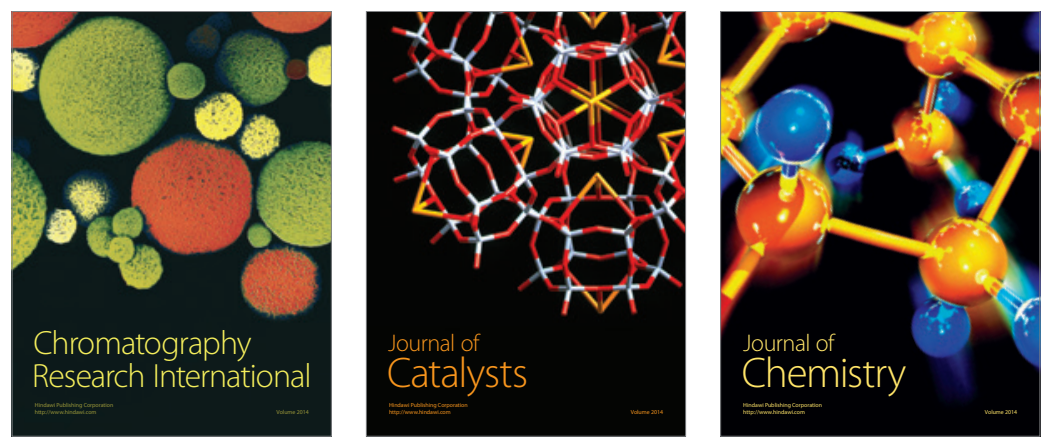
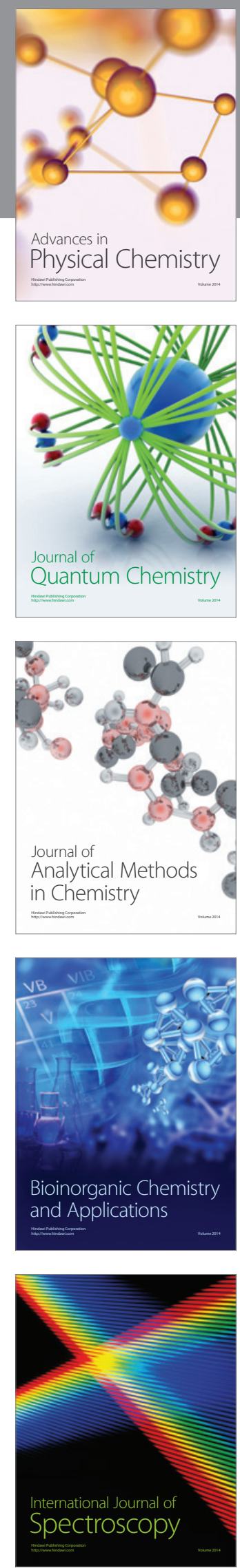